SVU- International Journal of Veterinary Sciences, 3 (2): 96-105, 2020.

Print ISSN: 2535-1826

Online ISSN: 2535-1877

CrossMark

Research Article

Open Access

\title{
Morphological features of pharyngeal roof of Egyptian geese (Alopochen aegyptiacus)
}

\author{
Mohammed Abdelsabour-Khalaf ${ }^{1^{*}}$, Yasser Ahmed ${ }^{2}$ \\ ${ }^{1}$ Department of Anatomy and Embryology, Faculty of Veterinary Medicine, South Valley University, Qena, Egypt \\ ${ }^{2}$ Department of Histology, Faculty of Veterinary Medicine, South Valley University, Qena, Egypt
}

\section{ABSTRACT}

The anatomy of the pharyngeal roof of Egyptian geese has been studied to define the structural features which may affect swallowing and food intake, in addition to provide a basis for bird pathology identification in this area. The results showed that the pharyngeal roof of geese was smooth with numerous scattered conical papillae of various sizes and had several openings of the sphenopterygoid salivary glands. Its length was $16.2 \mathrm{~mm}$, about 16.5 percent of the total length of the oropharyngeal roof. A common opening of both ear tubes; infundibular cleft, was measured $8.09 \mathrm{~mm}$ and extended caudally to pharyngoesophageal junction through shallow groove. The pharyngeal mucosa contained abundant mucous and serous glands associated with lymphatic nodules, in addition to accumulation of nerve cells. In conclusion there were some anatomical features of the pharyngeal roof of geese that are unique to this species and morphological changes to this area of the digestive tract can reflect adaptations to the bird's environment and mode of feeding.

Keywords: pharyngeal roof, geese, papillae, sphenopterygoid salivary glands.

DOI: 10.21608/svu.2020.35503.1066 Received: April 12, 2020 Accepted: June 16, 2020 Published: July 2, 2020.

*Corresponding Author: Mohammed Abdelsabour-Khalaf_E-mail: m_sabour@vet.svu.edu.eg Citation: Abdelsabour-Khalaf et. al., Morphological features of pharyngeal roof of Egyptian geese (Alopochen aegyptiacus) SVU-IJVS 2020, 3(2): 96-105.

Copyright: (C) Abdelsabour-Khalaf et. al. this is an open access article distributed under the terms of the creative common attribution license, which permits unrestricted use, distribution and reproduction in any medium provided the original author and source are created.

Competing interest: The authors have declared that no competing interest exists

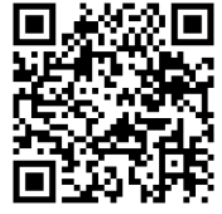




\section{INTRODUCTION}

The Egyptian goose is a medium-sized aquatic bird, classified as the order Anseriformes and the family Anatidae, usually seen in Africa specially around Nile valley and south of the Sahara desert (Newman, 1983). In birds, due to lack of soft palate, oropharynx refers to the mingled cavity which extends from the beak to the esophagus (Dyce et al., 2009). The boundary between the two cavities was dorsally placed at the junction between the choanal slit and infundibular cleft (King and McLelland, 1984). Due to differences in feeding habits, birds have different configurations of their oropharyngeal cavity, so the characteristics of the avian oropharyngeal cavity are important to recognize structural variations that may affect food intake and swallowing (Jayachitra et al., 2015). The anatomy of the pharyngeal roof in birds was insufficient in the available literature and lacks the requisite descriptions in particular anatomy of the pharyngeal roof in geese. This research was therefore conducted to clarify the gross, light and scanning electron microscopic characteristics of the pharyngeal roof.

\section{MATERIALS AND METHODS}

The present study used twelve healthy adult Egyptian geese aged between three to four months. The heads were collected directly after slaughter and submerged in $10 \%$ neutral buffered formalin for $48 \mathrm{~h}$, then washed in running tap water, and cut through one angle of the mouth to show off the pharyngeal roof. Morphometric analysis was done in detail for each bird, and the various measurements in millimeters (mean \pm S.E.) of the studied pharyngeal roof were taken by Digital Vernier Caliper. For light microscopic examination, the specimens were fixed for 3 days in $4 \%$ buffered formaldehyde at $4^{0} \mathrm{C}$ for paraffin embedding and treated to histological investigation as reported by Ahmed et al. (2013). Paraffin sections were sliced at a thickness of $3-5 \mu \mathrm{m}$ and stained with Hematoxylin and Eosin Bancroft and Gamble (2002). For SEM, the pharyngeal roof specimens were taken, fixed in a sodium phosphate buffered solution of $2 \%$ paraformaldehyde and $2 \%$ glutaraldehyde for $24 \mathrm{~h}$. The samples were washed in $0.1 \mathrm{M}$ phosphate buffer at $\mathrm{pH}=$ 7.4 , then dehydrated in ascending grades of ethanol followed by critical point-dried in liquid carbon dioxide followed by mounting onto stubs, and sputter coated with palladium and gold in a Bal-Tec sputter coater. Specimens were investigated and photographed using JEOL scanning electron microscopy (JSM-5400).

\section{Ethical approval}

The animal ethical committee of the Faculty of Veterinary Medicine, SVU, Egypt, approved the collection and handling of this study. These methods were performed following the guidelines of the institutional ethical committee of SVU, Egypt.

\section{RESULTS AND DISCUSSION}

\section{Gross anatomical and morphometrical studies}

The roof of pharynx extended from demarcation line between choanal and infundibular clefts to the pharyngoesophageal junction. The mucous membrane of the pharyngeal roof elevated caudally forming arched shaped border that exhibited clear line of demarcation between 
pharyngeal roof and esophagus (pharyngoesophageal junction). The morphometric study showed that the length of the pharyngeal roof is measured $16.2 \mathrm{~mm}$, about $16.5 \%$ from the total length of the oropharyngeal roof. It formed about $22 \%$ in the pigeon and 33\% in chicken (Mohamed and Zayed, 2003), in turkey $28.73 \%$ (Varsha et al., 2018), in addition to $15.19 \%$ in 60 days old duck (Madkour, 2011), 13.64\% in laughing dove and $27.18 \%$ in Japanese quail (Madkour, 2018). Those variations may be attributed to characteristics of the species. The surface of pharyngeal roof was smooth with numerous thin caudally directed papillae, more concentrated on both sides of infundibular cleft. These papillae arranged mostly caudally, and form curved row of pharyngeal papillae at arched pharyngoesophageal junction. In contrast, it forms the transverse rows of papillae in Southern lapwing (Erdoğan and Pérez, 2015), in guinea fowl (Jayachitra et al., 2015), in fowl (Gupta et al., 2015) and in turkey (Varsha et al., 2018), while absent in ostrich (Tajali et al., 2008). In the caudal part of pharyngeal roof, there was median longitudinal slit; infundibular cleft. It considers a common opening of both eat tubes. It measured $8.09 \mathrm{~mm}$ and its caudal angle extends caudally until the pharyngoesophageal junction with shallow groove. In turkey measured $6.93 \mathrm{~mm}$ (Sayed et al., 2016) , 8.04mm in 60 days old duck (Madkour, 2011), 10.97mm in ostrich (Tajali et al., 2008), 2.53mm laughing dove and 3.83 $\mathrm{mm}$ in Japanese quail (Madkour, 2018) (Fig.1).

\section{Scanning electron microscopical studies}

The pharyngeal roof characterized by various sized scattered and caudally directed papillae. These papillae were mainly conical in shape with broad base and pointed apices. The infundibular cleft appeared as elongated opening and guarded by elongated conical caudally directed papillae. The papillae increased caudally towards the pharyngoesophageal junction forming a curved row of caudally directed papillae (Fig.2). The rostral half of pharyngeal roof had longitudinal row of caudally directed papillae on its lateral side with numerous openings of sphenopterygoid salivary glands all over the pharyngeal surface (Fig.3). By SEM in section of pharyngeal wall showed many of sphenopterygoid salivary glands with its ducts opened in the surface of the pharynx in addition to pharyngeal muscles (Fig.4). Numerous small, fine, caudally directed papillae with pointed ends were observed in the duck around the infundibular cleft (Madkour, 2011). These papillae increased in number and its length towards the opening of the esophagus, where they formed a well-marked transverse row which marked the pharyngoesophageal junction (Hassouna, 2002). In addition to, in turkey, this junction's papillae were elongated, conical shaped and were caudally directed (Sayed et al., 2016), while this junction was absent in ostrich (Tajali et al., 2008). Functionally, the caudally directed papillae helped in swallowing and movement the food towards the esophagus (King and McLelland, 1984).

\section{Histological investigation}

The lining mucosa of pharyngeal roof of geese was consisted of lamina epithelialis and lamina propria. Lamina epithelialis was 
composed non-cornified stratified squamous epithelium with small keratinizing cone shaped pharyngeal papillae. The lamina propria was composed of dense connective tissue containing mixed sphenopterygoid salivary glands, that formed a large part of the glandular tissue. There were two types of salivary glands; branched tubular mucous glands and serous glands. The mucous one was lined by tall columnar cells, with basophilic foamy cytoplasm and flat basal nuclei, while serous glands were lined by pyramidal cells, with deeply acidophilic cytoplasm and rounded centrally located vesicular nuclei. The majority of sphenopterygoid salivary glands were associated with diffused lymphoid tissue aggregations of varying size. Below the glandular tissue, there was a small layer of irregular loose connective tissue comprising nerves and blood vessels. Moreover, accumulation of nerve cells; ganglia was also found in connective tissue of lamina propria, which consisted of pseudounipolar and multipolar nerve cells and both were surrounded by Satellite glial cells. (Fig. 5, 6). Generally, the lining of all oropharynx in birds were a stratified squamous epithelium (Calhoun, 1954; Fahrenholz, 1937; King and McLelland, 1984; Mclelland, 1975, 1979; Nickel et al., 1977; Warner et al., 1967). Hodges (1974) reported that the pharyngeal cavity of fowl had lining with non-cornified stratified squamous epithelium, in contrast in duck (Madkour, 2011) and in turkey (Sayed et al., 2016), the pharynx was lined by cornified stratified squamous epithelium. Tucker (1958) mentioned that in the animal's environment and condition affect both number and size of glands in oropharynx and the glands were well developed in dry-fed birds, such as seedlings or eating insects (King and McLelland, 1984). Lamina propria contained compound tubular mucous sphenopterygoid salivary glands in turkey (Sayed et al., 2016). Small simple tubular and large simple branched tubular mucussecreting glands were described in ostrich (Tivane, 2008) and in emu (Crole, 2011). Abundant lymphoid tissues was showed in connective tissue of salivary glands in the present study and was also cited in duck (Hassouna, 2002; Madkour, 2011), in fowl (Bradley and Grahame 1960; Hodges, 1974; Ohshima and Hiramatsu, 2000) and in turkey (Sayed et al., 2016) abundant lymphoid tissues was showed in connective tissue of salivary glands. In birds, this tissue had been described as pharyngeal tonsils (King and McLelland, 1984). The pharyngeal tonsils on the dorsal surface of the pharynx help to defend the body against infectious bacteria, viruses and other foreign organisms, and these tonsils are known as regular infection portals (Tajali et al., 2008).

\section{ACKNOWLEDGEMENTS}

The authors would like to thank South Valley University for funding.

\section{CONFLICT OF INTERESTS}

The authors declare that they have no conflict of interests. 


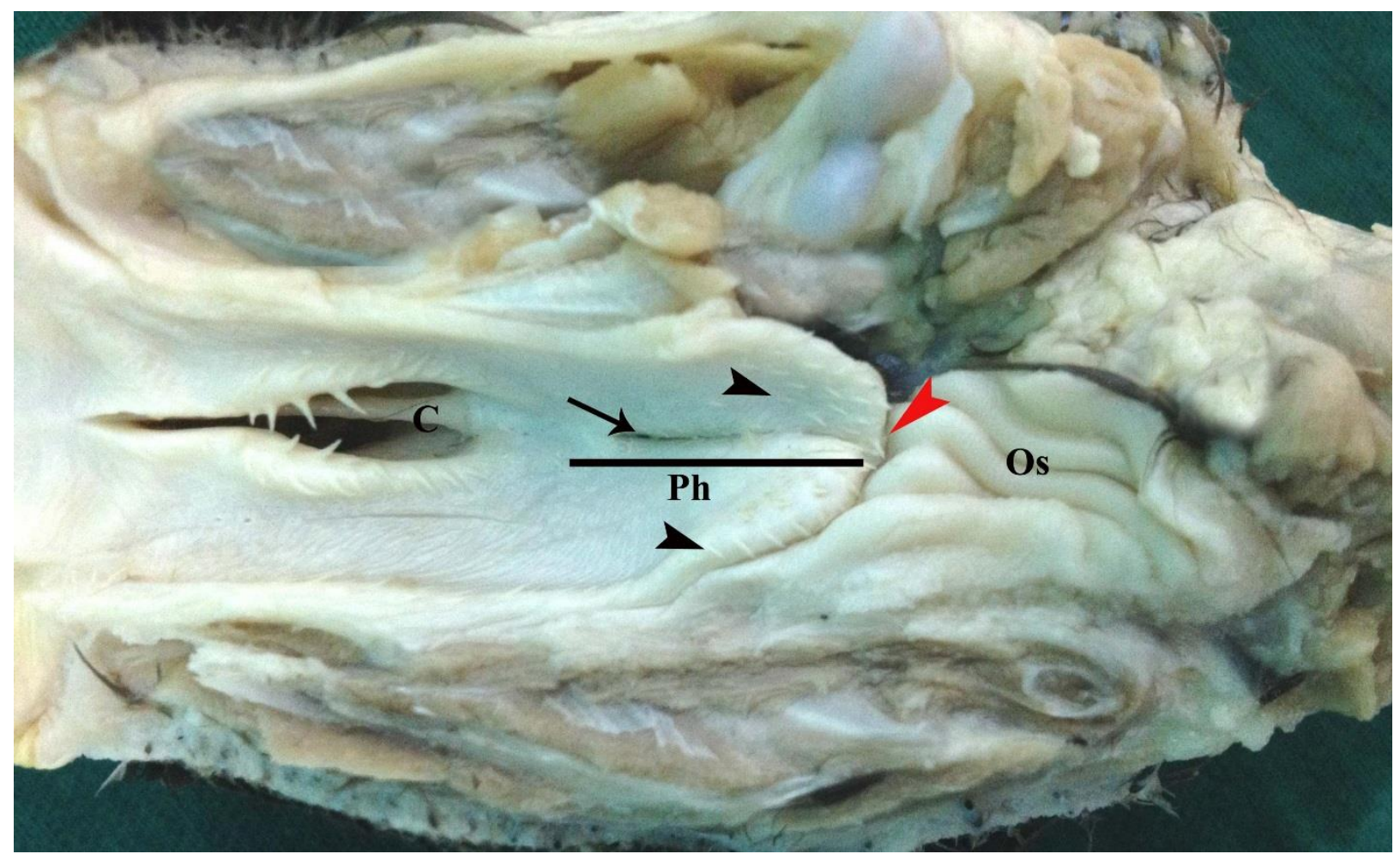

Fig.1: photograph of pharyngeal roof of Egyptian geese showing pharyngeal roof (ph), infundibular cleft (arrow), esophagus (OS), pharyngeal papillae (black arrowheads), pharyngoesophageal junction (red arrowhead), choanal slit (C).

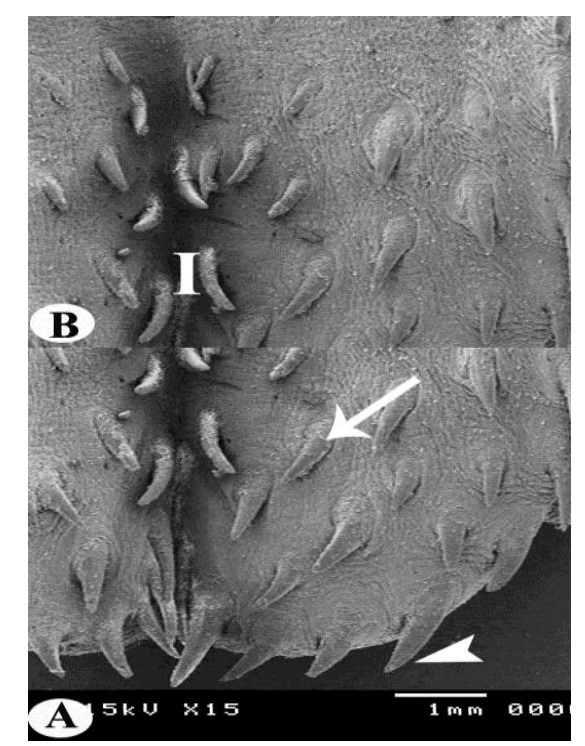

Fig.2: Scanning electron micrographs of the pharyngeal roof of Egyptian geese (A, B) showing infundibular cleft (I), conical pharyngeal papillae (arrow), pharyngoesophageal junction papillae (arrowhead). 

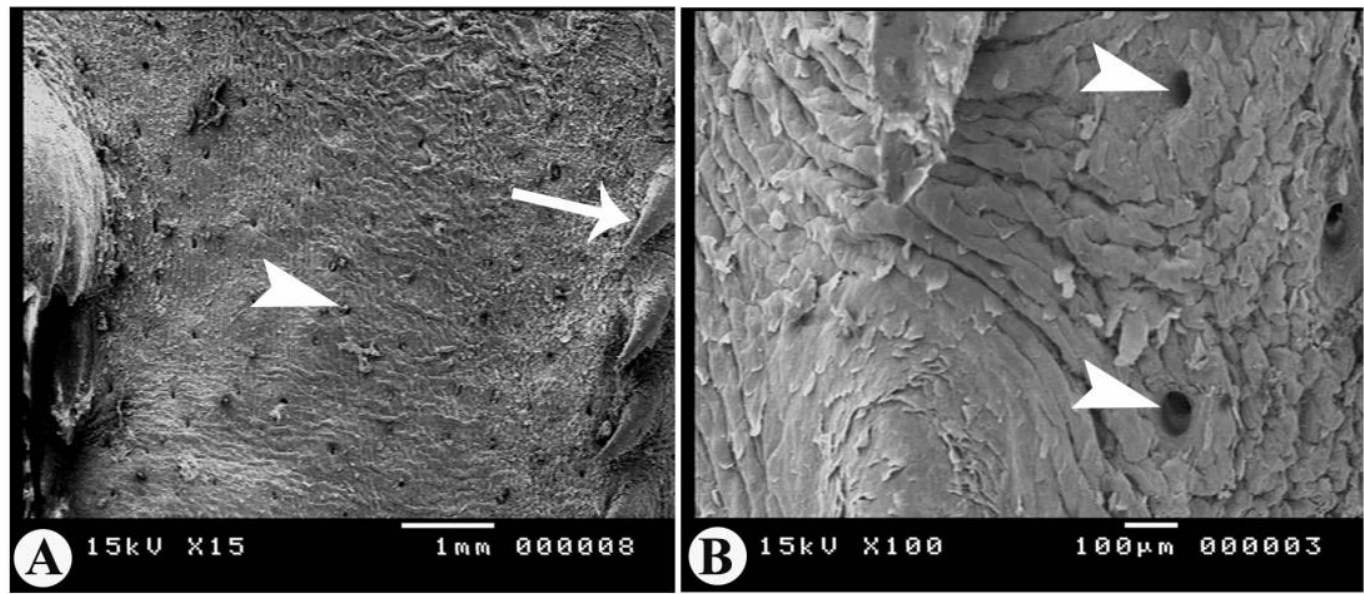

Fig.3: Scanning electron micrographs of the pharyngeal roof of Egyptian geese (A, B) showing pharyngeal papillae (arrow), sphenopterygoid salivary glands opening (arrowhead).

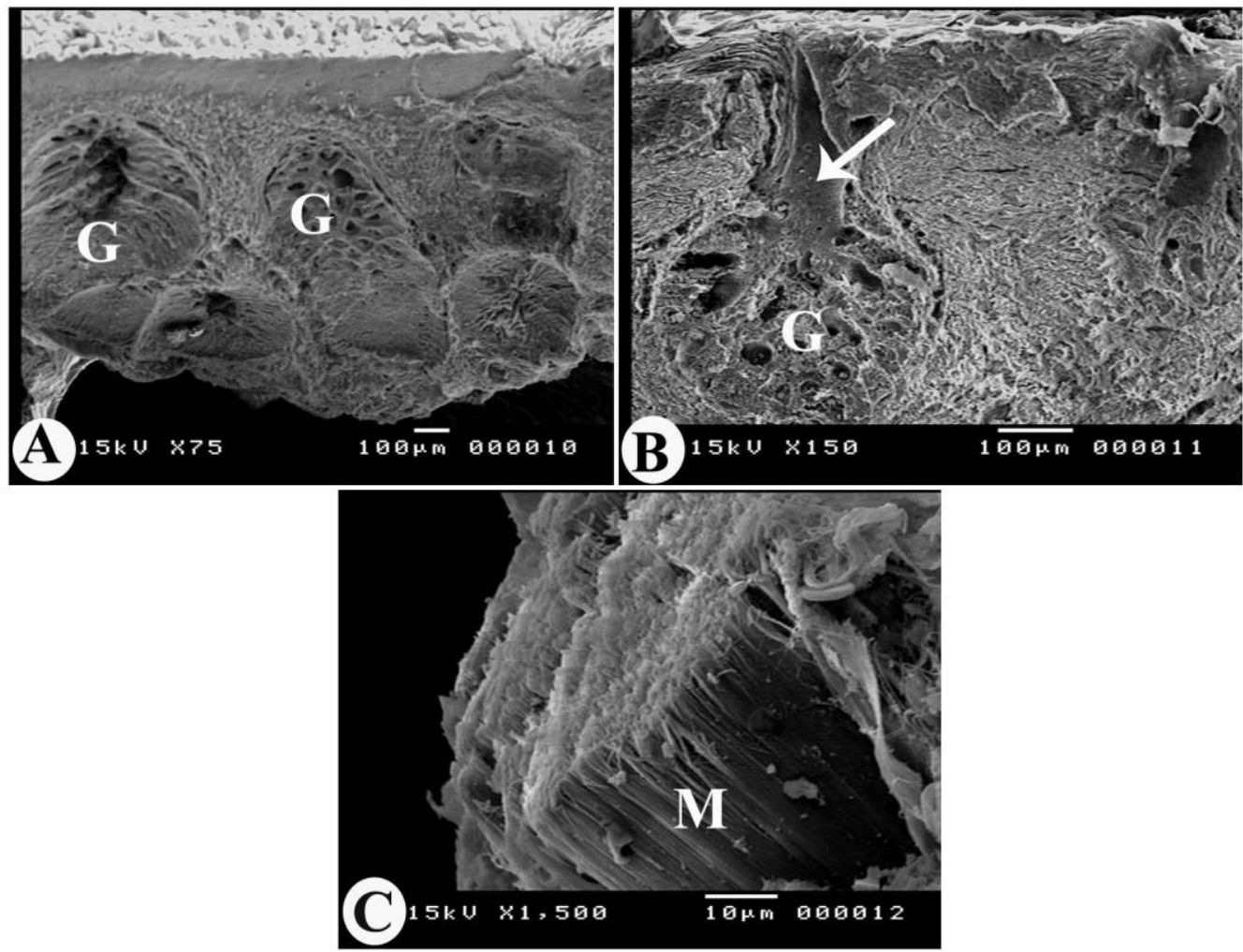

Fig.4: Scanning electron micrographs of the pharyngeal roof of Egyptian geese (A, B, C) showing sphenopterygoid salivary glands $(\mathrm{G})$, sphenopterygoid salivary glands duct (arrow), pharyngeal muscles $(\mathrm{M})$. 


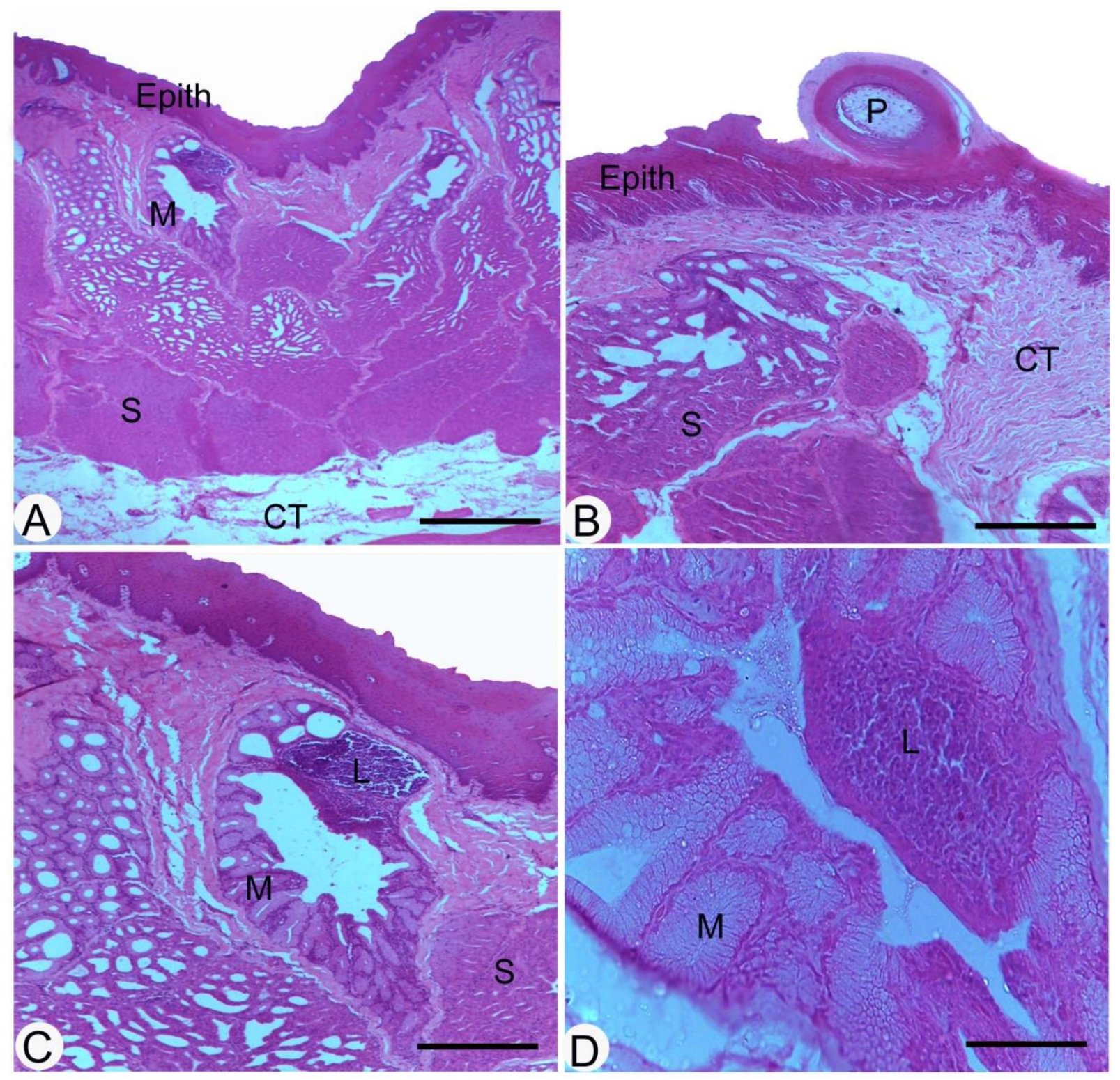

Fig.5: Photomicrograph of the pharyngeal roof of geese, showing stratified squamous epithelium with pharyngeal papillae "P", mucous gland "M", serous gland "S", lymphatic infiltration "L", connective tissue "CT". H\&E stain. 

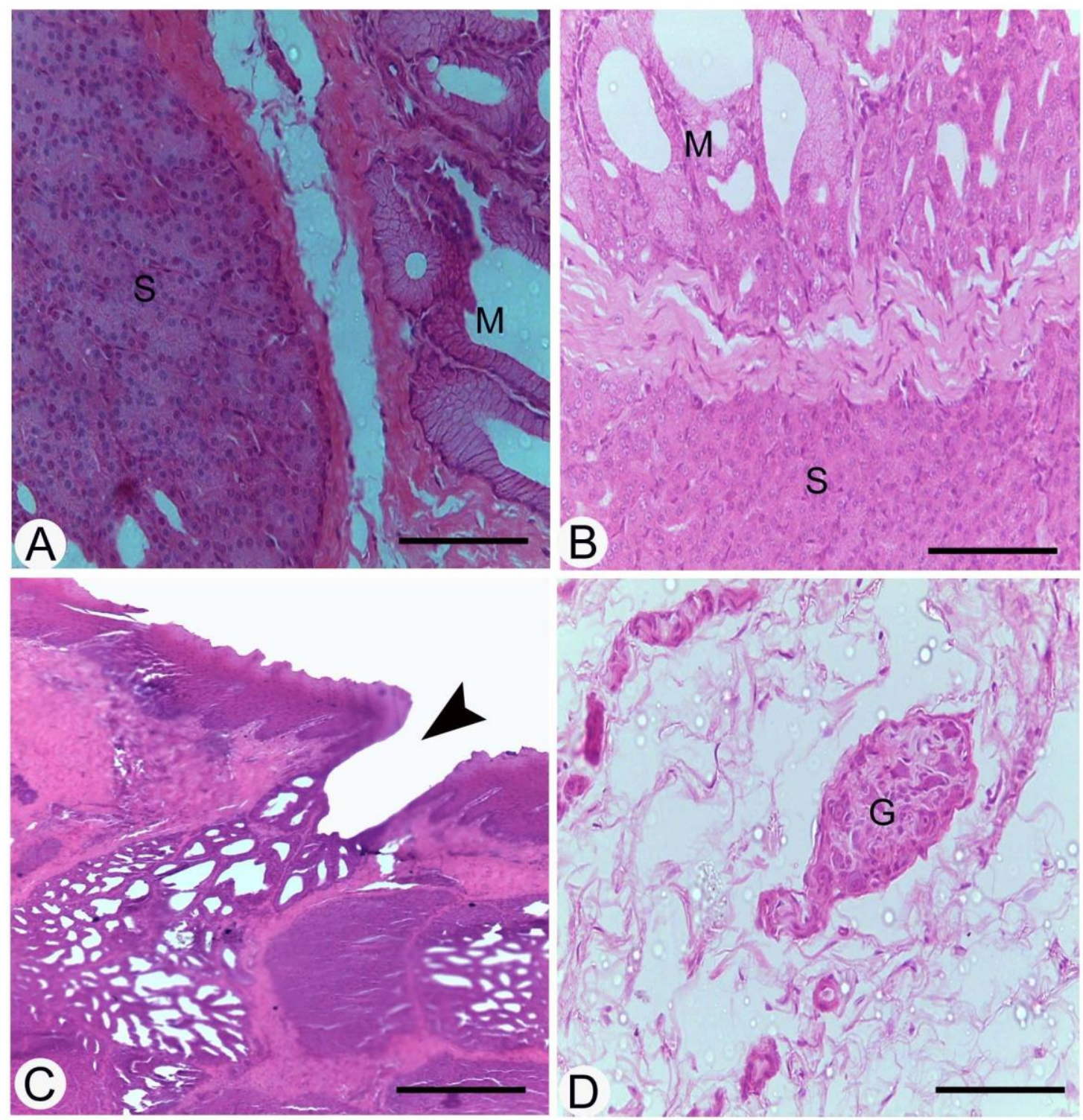

Fig.6: Photomicrograph of the pharyngeal roof of geese, showing mucous gland "M", serous gland "S", ganglia "G", salivary gland perforated epithelium (arrowhead). H\&E stain.

\section{REFERENCES}

Ahmed, Y.A., Soliman, S.A., Abdel-Hafez, E.A., (2013): Ossification of the femur and tibia of the post-hatching
Japanese quail. Pakistan Journal of Biological Sciences 16, 859.

Bancroft, J., Gamble, M., (2002): Theory and practice of histological techniques. 
5th London Edinburgh New York Philadelphia St. Louis Sydney. Toronto.

Bradley, O.C., Grahame , T., (1960): Digestive system in "The Structure of the fowl". 4th ed. Oliver and Boyed, Edinburgh.

Calhoun, M.L., (1954): Microscopic Anatomy of the Digestive System of the Chicken. Ames, Iowa: Iowa State College Press.

Crole, M.R., 2011. A gross anatomical and histological study of the oropharynx and proximal oesophagus of the emu (Dromaius novaehollandiae). University of Pretoria.

Dyce, K.M., Sack, W.O., Wensing, C.J.G., (2009): Textbook of Veterinary Anatomy. Elsevier Health Sciences. Philadelphia, London, New York and Sydney.

Erdoğan, S., Pérez, W., (2015): Anatomical and scanning electron microscopic characteristics of the oropharyngeal cavity (tongue, palate and laryngeal entrance) in the southern lapwing (Charadriidae: Vanellus chilensis, Molina 1782). Acta Zoologica 96, 264-272.

Fahrenholz, C., (1937): Drüsen der Mundhöle. In: Handbuch der vergleichenden Anatomie der Wirbeltiere,. edited by L. Bolk, E. Göppert, E. Kallius \& W. Lubosch. Berlin: Urban and Schwarzenberg:, 115-206.
Gupta, S.K., Pathak, A., Farooqui, M., (2015): Anatomy of Oropharyngeal Cavity of Fowl (Gallus domesticus). Indian Journal of Veterinary Anatomy 27.

Hassouna, E., (2002): Morphyological studies on the phyarynged cavity of duck, Anas boushius domesticus. Assiut Veterinary Medical Journal (Egypt).

Hodges, R.D., (1974): The digestive system, in The Histology of the Fowl. . London: Academic Press: 35-47.

Jayachitra, S., Balasundaram, K., Iniyah, K., Sivagnanam, S., Tamilselvan, S., (2015): Morphology of oropharyngeal cavity in guinea fowl (Numida meleagris). International Journal of Advanced Multidisciplinary Research IJAMR 2, 99-102.

King, A.S., McLelland, J., (1984): Birds, their structure and function. Bailliere Tindall, 1 St. Annes Road.

Madkour, F.A., (2011): Some developmental studies on the roof of the oropharynx of the duck. M.V.Sc. thesis submitted to South Valley University, Egypt.

Madkour, F.A., (2018): Characteristic features of the pharyngeal cavity of the laughing dove (streptopelia senegalensis aegyptiaca) and japanese quail (coturnix coturnix). Assiut Vet. Med. J. 64, 52-59.

Mclelland, J., (1975): Aves digestive system, in Sisson and Grossman's The Anatomy of the Domestic Animals,. 
edited by C.E. Rosenbaum, N.G. Ghoshal \& D. Hillmann. Philadelphia: W.B. Saunders Company: 1857-1867.

Mclelland, J., (1979): Digestive system, in Form and Function in Birds. Volume 1, edited by A.S. King \& J. McLelland. San Diego, California: Academic Press: 69-92.

Mohamed, S.A., Zayed, A.E., (2003): Gross anatomical and scanning electron microscopical studies on palate of some birds. . Assiut Vety. Med. J. 49, $1-17$.

Newman, K., (1983): Newman's birds of southern Africa. MacMillan, Johannesburg.

Nickel, R., Schummer, A., Seiferle, E., (1977): Digestive system, in Anatomy of the Domestic birds. . Berlin: Verlag Paul Parey: 40-50.

Ohshima, K., Hiramatsu, K., (2000): Distribution of T-cell subsets and immunoglobulin-containing cells in nasal-associated lymphoid tissue (NALT) of chickens. Histology and histopathology 15, 713-720.

Sayed, R.K., Saleh, A.M., Ahmed, A.K., Abdalla, K.E., (2016): Gross
Anatomical, Light and Scanning Electron Microscopic Studies on the Pharyngeal Roof of Turkey (Meleagris gallopavo): Comparative Study. Journal of Advanced Veterinary Research 6, 112-117.

Tajali, M., Mansouri, S.H., Poust, P.A., (2008): Gross anatomy of the oropharyngeal cavity in the ostrich (Struthio camelus).

Tivane, C., (2008): A Morphological Study of the Oropharynx and Oesophagus of the Ostrich (Struthio camelus). MSc dissertation, University of Pretoria, South Africa.

Tucker, R., (1958): Taxonomy of the salivary glands of vertebrates. Systematic Zoology, 7:74-83.

Varsha, G., Archana, P., Farooqui, M., Ajay, P., (2018): Anatomy of the oropharyngeal cavity of turkey (Meleagris gallopavo). Haryana Veterinarian 57, 178-182.

Warner, R., McFARLAND, L., Wilson, W., (1967): Microanatomy of the upper digestive tract of the japanese quail. American journal of veterinary research 28, 1537-1548. 